\title{
Contexto y representación ${ }^{1}$
}

Context and representation

Jaime Humberto Romero Cruz

\section{Introducción}

La representación ha jugado un papel importante en la comprensión que occidente ha elaborado. En particular, esta ha sido relacionada con maneras de comprender la lengua y el lenguaje. En este artículo, se aborda la pregunta de, si la noción de representación como reflejo, asumida por Benveniste (1966), es en realidad la noción cartesiana según la presenta Mockus (1988); si existe una diferencia entre tal noción de representación cartesiana y la acogida por Bajtín (1986) con relación al requerimiento de refracción, o si existe otra diferencia, con relación a la representación, que juega más para establecer distinciones en las concepciones sobre lenguaje expuestas de manera sucinta más abajo. Por último, se discute la definición mockusiana de representación.

Para cumplir estos propósitos, se presenta y describe la noción de representación cartesiana según Mockus la expone en el contexto, inferido en este texto, de dar plausibilidad a la definición de representación por él adoptada. Como manera de contrastar si la representación cartesiana es solo reflejo o también refracción incluso en procesos de matematización, se presenta y analiza la representación y su papel en un proceso específico de matematización en un aula de matemáticas. Finalmente, se somete a tensión, desde los resultados de tal análisis, la definición mockusiana de representación ligada a la configuración de secuencias de juegos de lenguaje conducentes al logro de acuerdos escuetamente ratificables.

Intentando así, aportar elementos para sustentar que la representación cartesiana no puede ser considerada, con justicia, ni solo reflejo de la realidad ni vehículo que conduce a los cartesianos a concebir la realidad como su reflejo; por lo tanto, la noción cartesiana de representación no puede explicar la diferencia de concepción acerca del lenguaje de Bajtín y Benveniste.

La representación permite compartir formas de vida de tal manera que aparecen lenguajes locales que la transforman y para estas -representación y su transformación- aparecen sentidos diferentes pero concatenados al inicialmente concebido. Es el diseño del profesor o si se quiere decir de otra manera, es el profesor instrumentado en el diseño, quien posibilita

1 Este trabajo es producto de las reflexiones que surgen del proyecto de la tesis doctoral Modelos y misconcepciones en situaciones de Aula. Una perspectiva pragmática, desarrollado en el marco del Doctorado interinstitucional en Educación en el Énfasis en educación matemática de la Universidad Distrital Francisco José de Caldas 
la presencia de la cadena de sentidos, de la toma de conciencia del acontecer ahí con una historia humana.

\section{Sobre enunciado y representación}

\section{En Bajtín}

Una manera de concebir el lenguaje puede obtenerse al seguir algunas propuestas de Bajtín. Para este autor, la unidad mínima del lenguaje resulta ser el enunciado concebido como un acto de palabra. Por lo tanto, es un acto poblado de intenciones debido a que la palabra pronunciada ha sido tomada por el enunciador de un contexto que remite a otros contextos y así indefinidamente. Con palabras de Bajtín (1986, p.121), en Cárdenas (2009b, p. 2):

(...) la palabra no está en un lenguaje neutral e impersonal (ipues el hablante no la toma de un diccionario!), sino en labios o en contextos ajenos, al servicio de intenciones ajenas: de aquí es de donde hay que tomarla y hacerla propia

Para comprender el enunciado como un acto de palabra es importante comprender la noción bajtiniana de contexto. Según Cárdenas (2009a, p.7), para Bajtín:

el contexto se compone de tres momentos: 1) un horizonte espacial compartido por ambos hablantes (la unidad de lo visible...); 2) el conocimiento y comprensión común de la situación, asimismo compartidos por los dos y, finalmente, 3) la valoración compartida por los dos, de esta situación

Entonces, se puede visualizarlo como una figura emergente, tridimensional y recursiva de relaciones pragmáticas y semióticas compartidas cuando dos hablantes al compartir situaciones específicas comparten sus horizontes espaciales, sus comprensiones y conocimientos, así como sus valoraciones ya que, al hacerlo, deben recurrir a las relaciones pragmáticas y semióticas previamente compartidas con y por otros hablantes actualizándolas en un espacio-tiempo específico. Tal figura podría ser esquematizada como sigue (figura 1):

\section{FIGURA 1.}

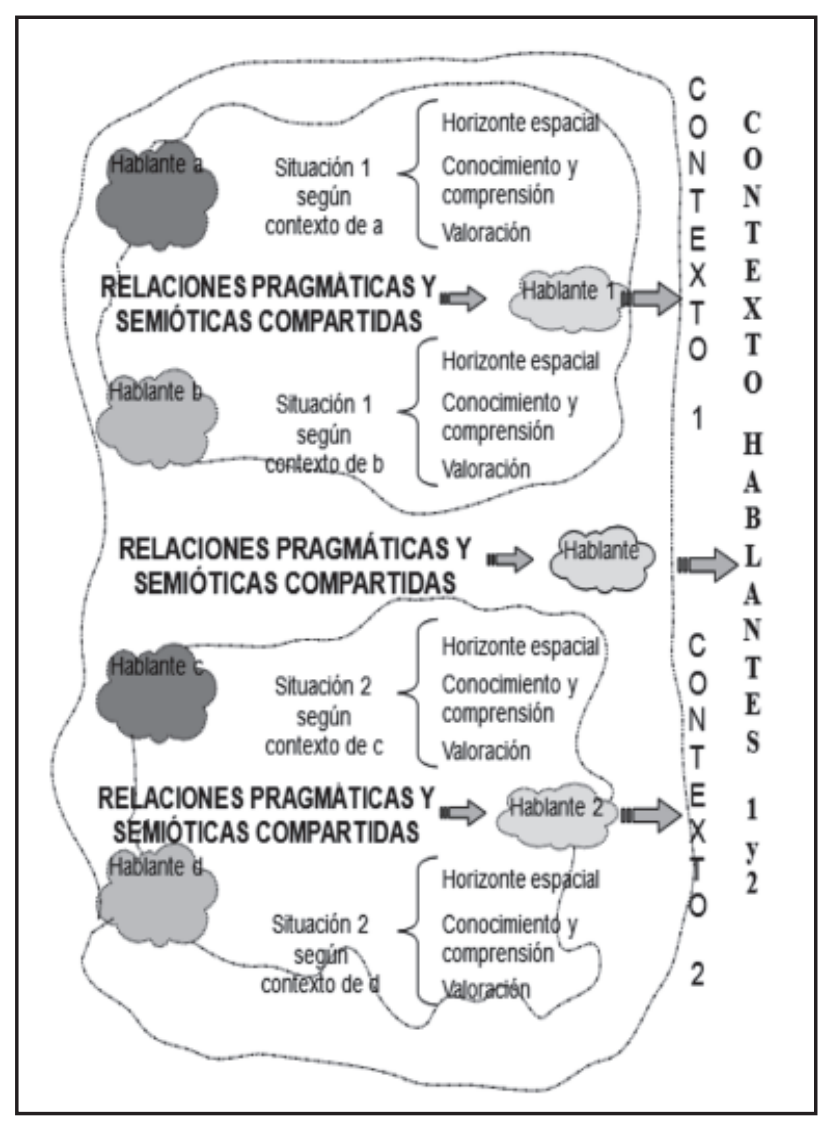

Esto permite ahondar más en lo que Bajtín propone acerca del enunciado en cuanto acto de palabra. Con respecto a esta última, el enunciador debe cumplir con una doble condición: 1) la toma de contextos ajenos y 2) la hace propia. El cumplimiento de esta doble condición conlleva a comprender un complejo, tomado en el sentido vigotskiano, tridimensional parcialmente ordenado, cuyos criterios organizativos son difícilmente elucidables, pues tal posibilidad yace tanto en el develamiento y reconstrucción de las historias -que han conformado los mundos de vida de los sujetos intervinientes y los significados de las palabras-, así como en la anticipación de posibles efectos producidos por la ocurrencia de la palabra en el acto de palabra. Entonces, para el enunciador existe un recorrido temporal triple. Desde el presente del acto hacia el tiempo de configuración del mundo de vida de sí mismo y de los demás; desde el presente del acto hacia los significados originarios de las palabras y desde el presente del acto hacia el futuro de efectos posibles. 
Con lo dicho anteriormente, se intenta establecer conexiones tanto con la caracterización de enunciado que Cárdenas (2009b, p.3) toma de Bajtín (1982, p. 263); (p. 305), como con el requerimiento de la existencia de un supra destinatario que Bajtín (1982, p. 305) fórmula para el enunciador,.respectivamente:

El enunciado, a diferencia de la oración, se caracteriza por diferentes atributos: se delimita por el cambio de los sujetos discursivos, tiene contacto inmediato con la realidad, se relaciona de manera directa con los enunciados ajenos, posee plenitud de sentido y capacidad para determinar la postura de respuesta del otro hablante, es decir, provoca respuesta, es estable, tiene conclusividad, etc.

El autor del enunciado, con una mayor o menor concientización presupone la existencia de un supradestinatario (tercero), cuya comprensión recíproca, absolutamente justa, se plantea o en una lejanía metafísica, o en un tiempo histórico remoto (el destinatario de escapatoria)

\section{En Benveniste}

Cárdenas (2009a, p.1) plantea, por una parte, que Saussure $y$ Benveniste asumen una actitud cartesiana del lenguaje enfatizando en la estructura de la lengua y en el carácter representacional que hacen del mundo y que, por ello, relegan la realidad que vivimos a simple reflejo de la representación:

Ferdinand de Saussure se refirió al lenguaje como un conjunto heteróclito, acaballado en todos los niveles de la vida social $y$, por eso mismo, inabordable para una ciencia. Esa característica lo movió a hacer recortes de índole epistemológico e histórico, desde los cuales pudiera construir un objeto accesible desde una aproximación científica. Ese objeto, la lengua, una vez definidos sus límites: la forma y sus enfoques: la sincronía y la inmanencia, se alió con la racionalidad de la forma para, de esa manera, ausentar la realidad y objetivarla desde la perspectiva de la representación.
Lo que se corrobora auscultando la afirmación de Benveniste (1966, p. 25):
El hombre siempre ha sentido $-y$ los poetas lo han frecuentemente cantado- el poder fun- dante del lenguaje, que instaura una realidad imaginaria, que anima las cosas inertes, que permite ver lo que todavía no es, que trae de nuevo lo que ya ha desaparecido. Es por eso que tantas mitologías, cuando tienen que ex- plicar que en el amanecer de los tiempos algo ha podido nacer de nada, han planteado como principio creador del mundo esta esencia in- material y soberana, la Palabra (...).

(...) en la que devela una concepción del hombre como esencialmente logocéntrico. Lo que en conexión con su concepción de la relación de equivalencia entre realidad del hombre en tanto sujeto hablante y el signo, obliga a sujetos hablantes, al menos de la misma lengua, a instaurarse en la misma realidad. En palabras de Benveniste (1966, p. 52):

Para el sujeto hablante, hay entre la lengua y la realidad, adecuación completa: el signo recubre y comanda la realidad, más aún, es esa realidad.

\section{Una diferencia acerca de la representación}

Afirma Cárdenas (2009a) que, a diferencia de Benveniste, al introducir Bajtín: 1) la comprensión como una condición sine qua non del lenguaje, 2) la necesidad de una relación semiótica entre los signos y 3) la relación entre las conciencias exigiendo un tipo de representación que no refleje sino que refracte, recupera el mundo de la vida y por lo tanto la carga ideológica del signo como determinada completamente por las relaciones sociales. Con palabras de Cárdenas (2009a, p. 9):

El tema de la comprensión tiene en Bajtín un indudable tono ético, (...) está atravesado por la relación semiótica entre los signos y por la relación entre las conciencias, situadas dentro de los puntos arquitectónicos del mundo de 
la acción. De acuerdo con lo primero, la comprensión se produce en el universo ético-cognoscitivo del contenido pero, por otro lado, se manifiesta como una condición sine qua non de la naturaleza del lenguaje que tiene que ver con que los signos no se dan puros sino unos en relación con otros, de modo que un signo, al darse en el entorno de otros signos, comprende a estos otros y es comprendido por ellos, lo que da lugar a la convergencia de puntos de vista, a la configuración de un territorio de lucha entre estos signos.

(...) Bajtín distingue entre la comprensión de signos con su carga ideológica, con su importancia en el campo de fuerzas de las ideas, con sus acentos y valoraciones, y el reconocimiento de señales estables, idénticas a sí mismas, referidas a objetos técnicos o a instrumentos de producción, distanciadas de los contextos de uso de la lengua.

\section{Acerca de una definición en Representar y disponer}

\section{El lugar de la definición y el tipo de argumentación que la sostiene}

Mockus (1988, p.150) define representación como "aquello que permite el cambio de un juego de lenguaje a otro". Sorprende que esta definición solo aparezca en la página 150 . ¿Por qué presentar una definición tan simple sólo después de 149 páginas?, ¿sucederá como aquél caso en el que Whitehead y Russell ${ }^{2}$ usaron más de 20 páginas del segundo tomo de Principia Mathematica para mostrar la verdad de la proposición $1+1=2$ ?

La respuesta a la segunda pregunta es evidente: no y sí. No, porque Whitehead y Russell hicieron una construcción racional basada en la pretensión de configurar un sistema exhaustivo ${ }^{3}$ de explicitación, vía el uso de definiciones y aceptaciones de reglas arbitrariamente dadas:

2. Una generación que no soporta el aburrimiento será una generación de escaso valor.

3. Volume 1 begins with a lengthy Introduction containing sections entitled "Preliminary Explanations of Ideas and
1. Signos básicos del lenguaje.

2. Formas de combinarlos para obtener expresiones legítimas.

3. Principios lógicos sosteniendo formas legítimas de razonamientos básicos.

4. Maneras legítimas de combinar estos razonamientos.

5. La aplicación de todos los aspectos anteriores sobre objetos específicos llamados elementos y conjuntos, sobre relaciones entre dichos objetos llamadas relaciones de pertenencia y de contenencia.

6. Sobre predicados de primer y segundo orden acerca de estos objetos y de estas relaciones.

7. La aplicación de todos los aspectos anteriores para producir objetos y relaciones clásicos de la aritmética así como expansiones discursivas probando la verdad enunciada.

Así, esta construcción racional delimita de manera estricta lengua y lenguaje, al punto de asimilar el uno a la otra reduciendo de manera drástica los sentidos posibles para los enunciados, las maneras de enlazarlos discursivamente y el propósito veritativo del discurso. Dicho de otra manera, se reducen drásticamente sentidos y modos de uso de las funciones discursivas de la lengua. Mientras que el discurso mockusiano no está configurado así y no pretende demostrar la verdad de lo argumentado sino su certeza.

Notations", "The Theory of Logical Types", and "Incomplete Symbols". It also contains Part I, entitled "Mathematical Logic", which contains sections on "The Theory of Deduction", "Theory of Apparent Variables", "Classes and Relations", "Logic of Relations", and "Products and Sums of Classes"; and Part II, entitled "Prolegomena to Cardinal Arithmetic", which contains sections on "Unit Classes and Couples", "Sub-Classes, Sub-Relations, and Relative Types", "One-Many, Many-One and One-One Relations", "Selections", and "Inductive Relations". Volume 2 begins with a "Prefatory Statement of Symbolic Conventions" It then continues with Part III, entitled "Cardinal Arithmetics", which itself contains sections on "Definition and Logical Properties of Cardinal Numbers", "Addition, Multiplication and Exponentiation", Standford Enciclopedia of Philosophy. Disponible en: http://plato.stanford.edu/ entries/principia-mathematica/\#COPM 
Sí, porque en ambos casos la función reflexiva argumentativa de la lengua es la que organiza el discurso en función de arrojar luz, de dar evidencia a la certeza existente en el enunciado objeto. Así pues, una misma forma de racionalidad emerge. La primera es una construcción racional, mientras que la segunda es una reconstrucción racional. El primer enunciado objeto problematizado es ' $1+1=2$ ', mientras que el segundo enunciado objeto problematizado es 'la representación es aquello que permite el cambio de un juego de lenguaje a otro'.

La posibilidad de problematización de los enunciados es una parte importante de la forma de racionalidad emergente que en cada caso $y$, a su manera, enriquece el carácter público de los juegos de lenguaje en los que cada enunciado aparece. Dicho enriquecimiento, en el sentido expuesto en Habermas (1987), está determinado por la medida en que se hacen explícitas reglas y modos del juego de lenguaje disponiendo los enunciados, que ocurran en el juego, para la crítica de las pretensiones de validez. Otra parte importante para tal racionalidad emergente es, según Mockus (1988, p.157), lograr "mayor fertilidad discursiva y posibilidades de universalizar argumentos y conclusiones". Podemos pensar que para Mockus la representación es, entonces, un medio que permite el paso progresivo entre juegos de lenguaje que van poniendo las condiciones para la posibilidad de llegar a acuerdos con-sentidos.

La plausibilidad de esta definición, que combina extrema generalidad referencial con una fuerte precisión en su función en el ámbito de la acción comunicativa discursiva, admitiendo por ello existencia mental ligada a la imaginación u objetivada mediante dispositivos gráficos y formas simbólicas de escritura útiles para una visualización compartida, es lo que, a nuestro parecer, Mockus argumenta.

\section{Notas iniciales sobre la reconstrucción mocku- siana de representación}

El autor empieza su reconstrucción acudiendo a la concepción de Descartes sobre representación como una relación inmediata de la conciencia subjetiva, con lo que, desde esa relación, se predetermina como objetivo. Así pues, lo que es cierto, lo objetivo, es lo que se deja representar; lo que se presta a esa relación inmediata. Todo lo sensible que pueda ser llevado a figuras extensionales, siguiendo las indicaciones de las Reglas para la dirección del espiritu, -ir de la complejidad de todas las dimensiones de lo sensible hasta lo simple considerando las dimensiones de a dos en dos y demás- para hacer visible en la representación clara y distintamente todas las diferencias, es porque toda diferencia clara y distinta en la representación puede y debe corresponder a diferencias reales. Lo cierto es verdadero y lo verdadero es.

Así pues, Mockus argumenta que para Descartes:

1. El acceso a lo representado implica siempre acceso a la representación clarificada de todas sus diferencias y de todas sus relaciones tomadas de dos en dos. La imagen inicial no es garantía de certeza, es decir, no es garantía de existencia de lo imaginado; sí lo es la representación generada mediante un cuidadoso proceso constructivo de extensionalización analítico y sintético que permite al espíritu una captación inmediata,

2. El ideal que debe orientar toda representación es el de la representación matemática.

En lo expuesto hasta aquí, la noción de representación cartesiana dada en Mockus, a primera vista, parece obedecer a una conceptuación de la representación que, vista según Bajtín, la aleja de ser signo y la aproxima a ser señal. Pero, ¿es plausible tal interpretación?

\section{Una advertencia.}

La nota de pie de página 165 debe servir para morigerar tal interpretación. En ella Mockus advierte:

(...) nos parece sin embargo, que (...) se puede exagerar la inmediatez y certeza de las representaciones cartesianas. Locke es quien emplea la metáfora del espejo (...) Descartes no 
puede valerse de esa metáfora para pensar la noción de representación. La "figura" que se le presenta con inmediatez al entendimiento presupone procesos de selección y transformación (extensionalización) (...)

(...) y se podría acudir en su respaldo a los distintos lugares del texto mockusiano que describen la actividad de matematizar, la mathesis, para generar comprensión acerca de los procesos de selección y transformación que están implicados, para que la representación llegue a ser inmediata para el entendimiento; es decir, para respaldar la convicción que, según Mockus, Descartes expresa acerca de la educabilidad de la captación inmediata, esta es:

3) La captación inmediata es educable en la medida en que se logre familiaridad con los procesos de extensionalización y de simbolización. Figuras y símbolos son medios posibilitadores de la extensionalización y de la simbolización, que dispuestos en listas, enumerados y recorridos de arriba hacia abajo y de abajo hacia arriba, permiten al entendimiento la intuición intelectual.

Sin embargo, debido a que la carga del requerimiento de procesos de selección y transformación para hacer intuible la representación, en Mockus queda ligada a la mathesis misma y no aborda con suficiente fuerza la problemática de la comprensión de la representación, aquí describimos el papel de la representación, en una actividad de matematización producida por un grupo de escolares de cuarto grado de primaria en el contexto de una clase de matemáticas.

\section{La representación en un proceso de mate-} matización en el aula

\section{Algunos aspectos de la organización de la clase}

En un experimento de enseñanza desarrollado en tres fases, cuyo equipo investigador incluyó al profesor (Cobb, Confrey, Disessa, Lehrer y Schauble, 2003), se configuró un contexto de clase que favorecía procesos de interacción, comunicación discursiva cooperativa y generación de sentido (Narváez, et. al , 2005).

\section{El modelo matemático pretendido}

Se trataba de proveer a los estudiantes de un curso de cuarto grado de primaria -10 años edad-con situaciones y problemas multiplicativos -vistos como oportunidades de aprendizaje- cuyo modelo matemático pudiera conducir a expresiones de la forma $y=a^{n}$.

El profesor concretó estos puntos de vista estimulando a los estudiantes a realizar trabajo conjunto, llevando memoria escrita de manera individual y a compartir sus producciones con el gran grupo (Narváez, et. al., 2005).

\section{Actividades propuestas y algunas reflexiones}

La primera actividad, La tira de papel y llenado de la tabla, vinculó acciones sobre una tira de papel con las acciones requeridas para llenar un formato, figura 2. Esto permitió a los estudiantes generar información y organizarla, instalándose en una representación, focalizando una relación entre dos tipos de mundos numéricos. La tarea tuvo el siguiente formato:

- Completo la tabla usando las tiras de papel.

1. Para llenar la tabla vamos a tener en cuenta las siguientes preguntas:

2. ¿Cuántos dobleces debo realizar en la tira de papel para obtener dos partes iguales?, ¿por qué?

3. ¿Cuál es el mínimo número de dobleces que puedo hacer para obtener 32 partes iguales?, ¿por qué?

4. ¿Cuántas partes obtendré si realizo ocho dobleces?, ¿por qué?

5. ¿Cuántas partes obtendré si realizo 10 dobleces?, ¿por qué?

Narváez, et., al (2005) describieron las producciones de los estudiantes agrupándolas en cuatro casos centrados en cómo éstos operaron para obtener los resultados para los dos últimos renglones de la tabla.

REVISTA CIENTÍFICA / ENERO -DICIEMBRE DE 2009 / No. 11 / BOGOTÁ, D.C. 


\section{TABLA 2.}

\begin{tabular}{|c|c|}
\hline Número de dobleces & Número de Partes \\
\hline & 1 parte \\
\hline & 2 partes \\
\hline & 4 partes \\
\hline & 8 partes \\
\hline & 16 partes \\
\hline & 32 partes \\
\hline & 64 partes \\
\hline 7 & 128 partes \\
\hline 9 & \\
\hline 10 & 512 partes \\
\hline 11 & \\
\hline 13 & 2.048 partes \\
\hline 14 & \\
\hline & \\
\hline & \\
\hline & \\
\hline
\end{tabular}

Cuatro maneras en que los estudiantes abordaron la última parte de la tabla: para pasar del $11^{\circ}$ al $13^{\circ}$ : 1) multiplicar el número de partes que hay en el nivel $11^{\circ}$ por dos, sin tener en cuenta el doblez número $12^{\circ}$; 2) multiplicar el número de partes que hay en el nivel $11^{\circ}$ por tres; 3 ) del $11^{\circ}$ al $13^{\circ}$, multiplicar el número de partes que hay en el nivel $11^{\circ}$ por cuatro, pero al pasar del $11^{\circ}$ al $14^{\circ}$, multiplicar por seis; 4) para pasar del $11^{\circ}$ al $13^{\circ}$, multiplicar el número de partes que hay en el nivel $11^{\circ}$ por cuatro, y al pasar del $11^{\circ}$ al $14^{\circ}$, multiplicar por ocho.

Según la descripción elaborada, se puede ver que los estudiantes percibieron de diversas maneras la relación entre los mundos numéricos pretendidos y que, dentro de esta diversidad de interpretaciones, aunque unas discrepan de la pretendida por el profesor, dado que no satisfacen criterios de corrección, fueron tomadas como provisionales y contrastables con interpretaciones de otros o con interpretaciones nuevas generadas en otros momentos por ellos mismos al abordar situaciones similares. Así son las producidas, por ejemplo, en la siguiente tarea:

- Resuelvo el siguiente problema:

"En un viaje a Egipto, encontré a un hombre con dos esposas. Cada esposa tenía dos camellos; cada camello tenía dos sacos; cada saco tenía dos gatos; cada gato tenía dos gatitos. ¿Gatitos, gatos, sacos, camellos y esposas, cuántos iban a Egipto?"

- Explico el procedimiento que usé para resolver el problema.

- Represento la situación anterior por medio de un dibujo.

- Describo las operaciones llevadas a cabo para la solución del problema.

1. ¿Cómo harías para explicarle a uno de tus compañeros el problema y la forma de solucionarlo?

Los estudiantes elaboraron sus representaciones. En la figura 3 se muestra una secuencia de dibujos presentados:

\section{FIGURA 3. Representaciones de enunciado} viaje a Egipto
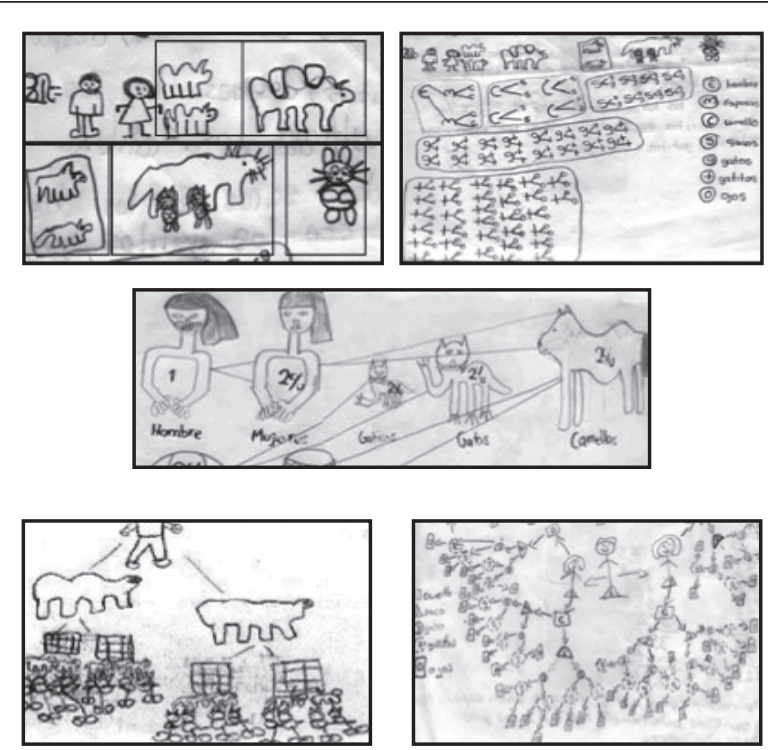

Una mirada a las representaciones presentadas.

El primer cuadro presenta el dibujo de la situación realizado por un niño que pone de relieve la relación entre cada personaje y sus dos correspondientes -hecho aquí visualizado encerrando cada grupo en rectángulos- acudiendo a mostrarlos 
por grupos según el orden en que se lee el texto del enunciado.

El segundo cuadro muestra el empleo a fondo de este mismo niño para dibujar su solución a la pregunta formulada en la situación: aplicando reiteradamente la relación uno a dos que hizo visible en su representación del enunciado, como se puede observar en cada uno de los segmentos visibilizados por encerramiento. Excepto el primer segmento, estos hacen visible los elementos de dos niveles consecutivos y las relaciones entre ellos. Asimismo, los segmentos se relacionan entre sí mediante proximidad física, siguiendo el orden derecha a izquierda, según la forma dada por la escritura en renglones y manteniendo un elemento intermediario, de tal manera que los elementos de segundo nivel en un segmento son los elementos de primer nivel en el segmento siguiente.

Así, se puede afirmar que el estudiante ha segmentado bajo un doble criterio: mostrar la relación de todos los elementos de un nivel con los del nivel siguiente y vincular los distintos segmentos entre sí.

\section{Configurando un sistema de representación.}

El niño generó un proceso de simbolización elucidando su punto de vista. Recurriendo a signos culturalmente elaborados, construyó un sistema de símbolos en el que resignifica y diferencia signos: letras, para representar objetos; líneas dirigidas, para representar relaciones entre estos objetos; encerramientos, para representar agrupamientos de relaciones relacionados entre sí mediante encadenamientos temáticos que respetan el orden del lenguaje escrito.

El niño, recurriendo a signos culturalmente elaborados, reitero, fue configurando un sistema de representación y puso de manifiesto en esta acción su comprensión del carácter convencional y funcional del simbolismo configurado. Esto es, el niño comprendió que: 1) el signo puede ser cualquiera -como lo atestigua el uso de distintos signos para gatos y gatitos-; 2) el signo está en relación con otro signo; 3 ) no obstante su arbitrariedad, el signo debe ser comprendido por lo menos por otro compañero, así que él le debe permitir vincular las representaciones con el enunciado verbal inicial, por tal razón, el signo exige definición; es decir, debe funcionar en posibles procesos comunicativos; y 4) el haz de signos debe funcionar para resolver la tarea matemática pedida. La configuración de un sistema de representación puede notarse también en los otros dibujos mostrados.

Es de resaltar, nuevamente, la diversidad de representaciones, y por lo tanto de puntos de vista expresados por los estudiantes. Por ejemplo, en los dos últimos recuadros, aparecen representaciones, organizaciones de signos que revelan aspectos de simetría no dispuestos en las anteriores. Asimismo, se resalta ahora por vez primera que, precisamente durante la segunda fase del experimento de enseñanza, el profesor enfatizó "La búsqueda de distintas formas de representar las situaciones", y que esto "generó una mirada más estructural sobre las mismas" (Narváez, et. al., 2005), ubicando la importancia de la transición desde representaciones tabulares a diagramas de árbol.

La transición antes aludida parece estar conectada con la comprensión de aspectos normativos incorporados en los sistemas de representación por ser convencionales $y$, también, por ser funcionales tanto en los procesos comunicativos como en los procesos resolventes. Así, cuando el profesor pidió a los estudiantes efectuar la siguiente tarea:

- Represento el problema de los dobleces de la tira de papel.

¿Qué pasa con cada parte de la tira cuando se realiza un nuevo doblez?

Ellos realizaron mayoritariamente representaciones como la mostrada en la figura 4, que dependen de una disposición que sigue la de los diagramas de árbol y respondieron la pregunta de las siguientes maneras:

- "Se va aumentando; cada vez que se hace un doblez, se hacen más partes".

- "Cada parte se va doblando por 2 cada parte". 
FIGURA 4.

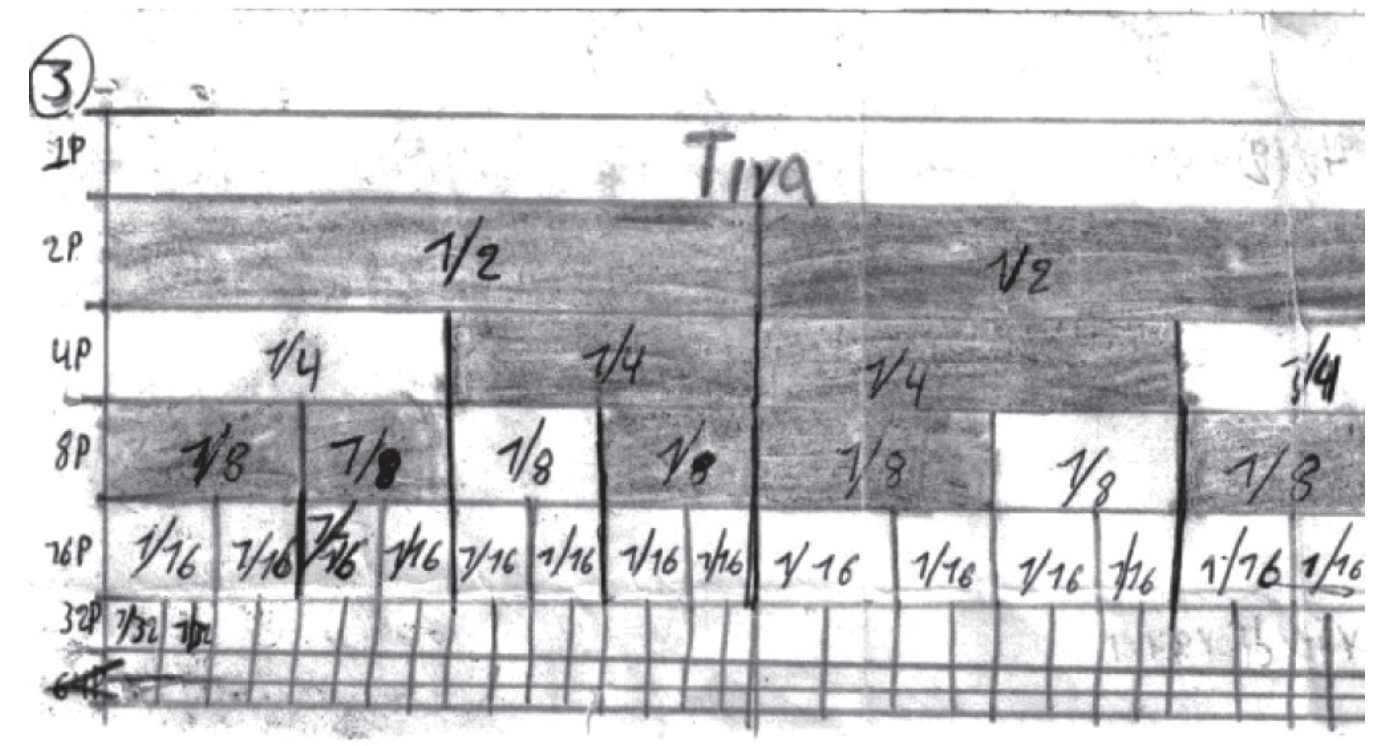

- "Lo que pasa con cada parte de la tira es que a lo que se realiza el nuevo doblez, el número de fracciones o partes se dobla".

- "Cuando se realiza un número de dobleces se multiplica X2 y se dobla”.

- "Si hago un nuevo doblez obtendré dos partes iguales, y si hago otro doblez, esta parte se divide en dos, y obtendré dos partes iguales".

Al comparar lo expresado por los estudiantes durante el desarrollo de esta actividad, con lo realizado por ellos en la actividad inicial La tira de papel y llenado de la tabla, Narváez, et. al., concluyeron:

vemos que las primeras afirmaciones referían exclusivamente las acciones sobre la tira de papel, pero cada vez que se profundiza en la situación, aparecen explicaciones que involucran un tipo de operación que satisface las condiciones del problema y con la que ganan economía de acciones y de pensamiento ("hago otro doblez, esta parte se divide en dos, y obtendré dos partes iguales") hasta establecer relación entre lo que se hace primero con la tira de papel y la operación que se involucra ("Cuando se realiza un número de dobleces se multiplica X2 y se dobla").
Convergencia como condensación de diversidad representacional

El grupo investigador concluye que hay una convergencia hacia la manera de ver la relación entre los mundos numéricos, prevista por el profesor; pero, esta convergencia ha llevado tiempo. Ha puesto en juego una intención mediante un diseño que moviliza, de manera conjugada y compleja, tanto una concepción de aprendizaje ligada a la enseñanza como la instrumentación técnica requerida para objetivar este diseño.

Por ejemplo, el constante interjuego entre maneras de representar vinculando tipos de acción -doblar papel, contar partes, organizar e inferir información, entre otros- y tipos de representación -tabular, diagramas de árbol-, vinculando tipos de acción y formas de comportamiento -analítico, sintético, generalizador, reflexivo, dialógico- que recorre buena parte del diseño, se basa en una teoría del aprendizaje que tiene en cuenta que los procesos de hacerse a los medios de expresión requieren del uso de esos medios -hacer- así como el dominio de las condiciones de uso -reflexión sobre el hacer-. De manera particular, insistió en acciones que sincrónicamante producían unidades aditivas - uno, dos, tres y más dobleces- y unidades multiplicativas -dos, cuatro, 
ocho y demás partes-; en determinar el comportamiento de los dos mundos numéricos y los tipos de unidades que los engendran. Pero, en tanto todos estos mundos y determinaciones son decantación, condensación de distintos puntos de vista puestos en juego, para sí y para los otros, a manera de dibujos, tablas, palabras pronunciadas y escritas, también son producto del diseño que permitió el intercambio y la condensación.

\section{Hibridación como forma de condensación}

De sistemas de representación.

La representación en la figura 4 expone configuraciones -acciones físicas, relaciones entre acciones físicas, objetos matemáticos: fracciones, secuencias de fracciones, numerosidad, relaciones entre cantidades- hibridando dos tipos de representaciones diagramáticas, tabular -dispone información- y árbol -dispone relaciones espacio temporales-, con tipos de representaciones aritméticas, decimal, partetodo; geométricas, magnitudes, partes; algebráicas, indiciales, funcionales, operatorias 'veces $x 2$ '.

\section{De formas de representación.}

Se examinarán inicialmente las representaciones producidas por dos niños, dando respuesta al cuarto ítem de la siguiente tarea:

Tengo en cuenta la cantidad de arvejas iniciales, y elijo un número del 2 al 6 con el que puedo hacer una cantidad de grupos sin que me sobren ni me falten arvejas. Los grupos deberán tener como cardinal el número escogido.

- ¿Cuántos grupos tengo inicialmente?

- ¿Cuál es el número de elementos que tiene cada uno de los grupos?

- ¿Cuántos grupos tengo después de hacer las agrupaciones con el número escogido?, ¿por qué?

- Realizo grupos de los grupos, con la cantidad escogida inicialmente. Escribo los resultados anteriores en una tabla (figura 5).

- Escribo los procedimientos llevados a cabo durante el desarrollo de la actividad.

\section{FIGURA 5.}

\begin{tabular}{|c|c|c|c|c|c|}
\hline Cantidad & \multirow{2}{*}{$\begin{array}{c}\text { Número } \\
\text { de }\end{array}$} & de elementos & Cantidad & \multicolumn{3}{|c|}{$\begin{array}{c}\text { Número de grupos } \\
\text { elementos }\end{array}$} & $\begin{array}{c}|c| \\
\text { por grupos grupos }\end{array}$ & grupos & $\mathbf{1}^{\text {a. }}$ & $2^{\text {a. }}$ & $3^{\text {a. }}$ \\
\hline & & & & & \\
\hline & & & & & \\
\hline & & & & & \\
\hline
\end{tabular}

- Represento cada uno de los pasos seguidos al realizar las agrupaciones.

Las dos representaciones aparecen en la figura 6 , la de 243 en base 3, nombrada R1, y la otra de 27 en base 3, nombrada R2. El punto de vista que dispone el niño en $\mathrm{R} 1$, sin duda refleja varios aspectos de la potencias enteras de un número entero dado: existencia de niveles de agrupamiento -tres, tres de tres, tres de tres de tres, tres de tres de tres de tres, y demás- una manera constante para pasar de un nivel dado al siguiente, lo que involucra reconocer cuáles son las unidades del nivel dado; la generación de una nueva unidad del siguiente nivel agrupando tres de estas unidades y la puesta de la siguiente hipótesis de trabajo: se puede actuar con las unidades recién generadas de la misma manera que con las anteriores unidades. Es decir, refleja la postulación de una relación entre la potenciación entera y la recursividad.

Ahora bien, el punto de vista que dispone el niño en $\mathrm{R} 2$, además de reflejar los aspectos anteriores, involucra un nuevo aspecto al introducirle forma, organización espacial, a la unidad que itera recursivamente. El aspecto de la forma impone mayor

\section{FIGURA 6.}

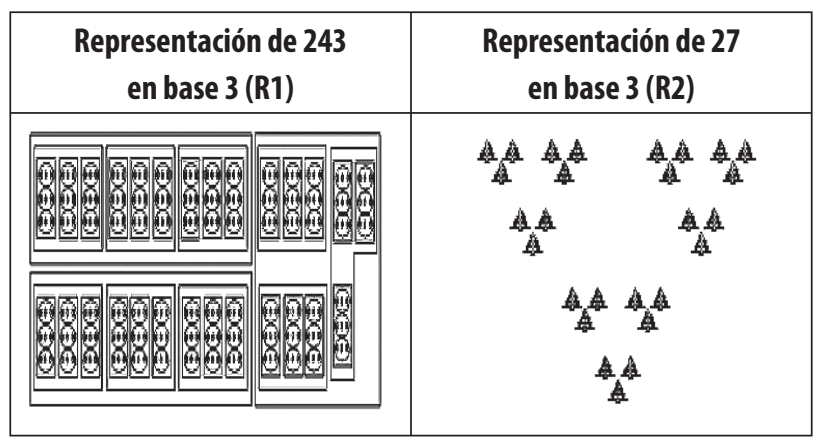

REVISTA CIENTÍFICA / ENERO -DICIEMBRE DE 2009 / No. 11 / BOGOTÁ, D.C. 
visualización a la organización recursiva de la potencia. El punto de vista que este niño dispone en su representación del número dado vincula estructura recursiva de la potencia entera de un número entero con la organización recursiva de la forma. Hace visible la integración y la diferenciación recursiva entre las partes y el todo.

De formas particulares de representación con un esquema comunal y local de representación.

Se aborda la cuestión examinando algunas representaciones verbales que los niños elaboraron como respuesta a la tarea que involucró seguir un diagrama, dibujado en una gran cartelera, como el de la figura 7.

La escuela: elaboro una historia a partir del diagrama.

Algunos enunciados de los estudiantes fueron:

- "La escuela tiene 5 salones, cada salón tiene 2 pupitres, cada pupitre tiene 3 sillas, cada silla tiene 1 niño, cada niño tiene 2 cuadernos".

- "En un jardín hay 5 bebés, cada bebé tiene 2 maracas, cada maraca tiene 3 pepitas, cada pepita tiene 1 hueco, cada hueco tiene dos plastilinas".

- "En una escuela hay 5 bloques, en cada uno de los bloques hay dos salones, en cada uno de los salones hay 3 pupitres, en cada uno de los pupitres hay una persona, que tienen dos esferos cada una”.

Cada niño visualizó en el diagrama la representación de una situación multiplicativa; pero, la configuró desde su propia mirada logrando hacer una historia corta coherente. En cada historia producida hay una toma de posición doblemente pertinente; con relación a los elementos y sus relaciones: en su mundo de vida es coherente tanto que el elemento de un nivel se relacione con el del siguiente -escuela con bloques, bloques con salones y otros- como que todos los niveles y sus relaciones conformen el mundo escolar descrito; y, asimismo, con relación a la clase de matemáticas: en la medida en que cada elemento de un nivel se relaciona con tantos elementos del nivel siguiente, como lo dispone el

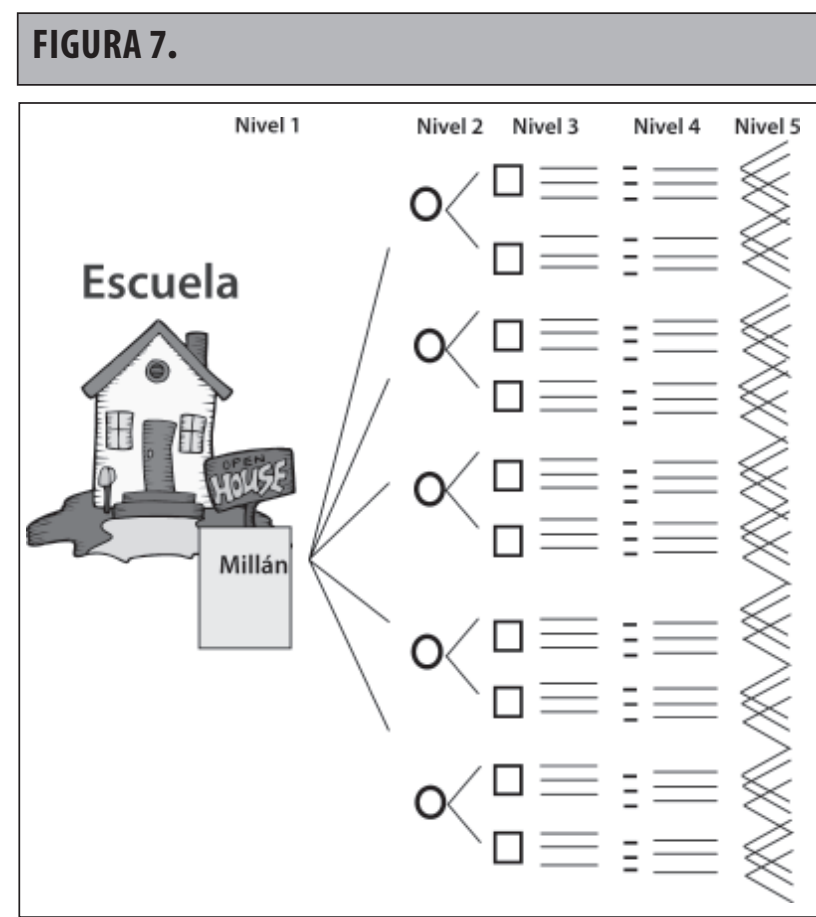

diagrama y en la medida en que estas producciones están dispuestas para ser presentadas a otros, es decir, con un sentido dialógico.

De tal manera que es posible observar que de cada una de las descripciones verbales producidas por cada niño, hibrida una representación proveniente de su mundo de vida con un esquema de representación genérico que involucra signos de relación multiplicativa simbólicamente interpretados por la comunidad local, mientras dispone signos que indican objetos a ser relacionados.

De representaciones por consenso normado.

Poco a poco los estudiantes fueron creando y usando expresiones verbales para describir la multiplicación repetida. Los niños estabilizaron la forma expresiva veces por para describir que se repetía la multiplicación, Así, seis veces por dos, conduce a $2 \times 2 \times 2 \times 2 \times 2 \times 2$. Una vez estabilizaron esta expresión, el profesor propuso la siguiente tarea, incorporada dentro de la tercera fase del diseño, presentada oralmente a los estudiantes durante el desarrollo de una clase:

Proponer cómo simbolizar la expresión "6 veces x 2", utilizando la menor cantidad de signos posible. 
Durante la clase, los estudiantes fueron pronunciando y escribiendo en el tablero las siguientes cuatro alternativas:
1) $6(\mathrm{v} 2)$
2) $2^{6}$
3) $6 v(2)$
4) $6^{\mathrm{v2}}$

Las simbolizaciones 1 y 3 parecen apócopes de la representación oral, seis veces por 2, cuya forma escrita, 6 veces $x 2$, venía siendo usada. Una discusión entre los niños que las propusieron se centró en el lugar del paréntesis, dado que su papel es el de reemplazar las expresiones por y $x$; así que, $6(\mathrm{v} 2)$ se debe leer seis por veces dos, mientras que $6 \mathrm{v}(2)$ conduce a seis veces por 2. La cuarta opción empieza a desprenderse del orden de pronunciación y del de escritura, desapareciendo el paréntesis y dejando en manos de la forma, la sintaxis, tanto la presencia como el significado de cada uno de los símbolos en el conjunto $\{$ por, $x,()\}$ hasta ahora usados. Esta manera de proceder, más que hacer una conversión de una expresión hecha con signos de la lengua natural, u otra que combina estos signos con signos aritméticos hacia otra expresión que solo usa signos aritméticos, pretende dejar patente en la nueva forma expresiva el papel diferente que juegan los números que la conforman en relación con la operación que refieren. $\mathrm{Al}$ respecto, afirman Narváez, et. al.:

(...) el estudiante que propone la cuarta opción argumenta que los papeles que desempeñan los números involucrados son distintos, y por lo tanto esto debe diferenciarse. La manera que se le ocurre es a través de hacer tamaños diferentes para los signos: la "v" y el dos iguales entre sí, y más pequeños que el 6.

\section{FIGURA 8.}

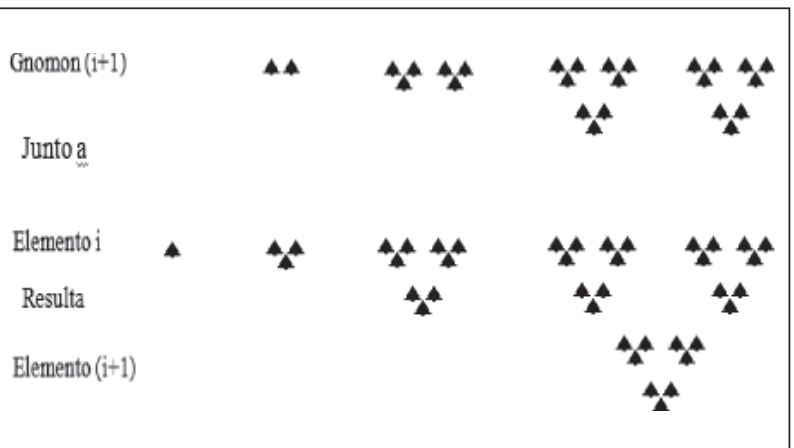

La segunda opción emergió como una toma de posición de un estudiante frente al enunciador que produjo la opción de simbolización anterior. En ella se puede reconocer que la forma de la expresión recoge de la anterior intervención la posibilidad de diferenciar el papel del número mediante el uso de tamaños. Además, relaciona el tamaño del número en la expresión, con el hecho de si está elucidado o no en la operación vista como multiplicación repetida. Narváez, et. al., recurriendo a lo dicho por el niño que la propuso:

(...) el dos lo dejo grande, porque es la cantidad que voy a multiplicar varias veces, y el seis lo dejo pequeño porque es el que me va a indicar el número de veces que tengo que hacer la operación.

Concluyen que:

(...) el estudiante mejoró una propuesta colectiva que reconoce que los signos deben representar cantidades de distintas naturaleza, -el dos representa la unidad de crecimiento, el seis las veces que se reitera la acción sobre la unidad inicial- e importancia relativa en la situación -el dos permanece durante el proceso, por eso es más grande, el seis es sólo un momento del mismo, por eso es más pequeño- por lo tanto, esas diferencias se deben notar en la escritura del símbolo.

Las normas son de dos clases según su origen, la pronunciada por el profesor en la tarea y la dispuesta mediante condensación del cúmulo de actividades realizadas, incluyendo hacer reflexión sobre el hacer, y modos y medios de realización.

Por una parte, lo descrito en el numeral 3.1 como ejemplo de la representación en la elaboración de un proceso de matematización, extensionalización, deja claro que la metáfora del espejo efectivamente no es suficiente para comprender la representación cartesiana y brinda credibilidad a la advertencia presentada por Mockus. Por otra parte, esta descripción muestra un proceso de construcción de acuerdos logrados en una clase de matemáticas mediante procesos de hibridación 
acogidos y estimulados en el diseño del profesor. Pero, ¿esto apoya la plausibilidad de la definición mockusiana de representación?

\section{Notas intermedias sobre la reconstrucción de representación en Mockus}

Otras dos concepciones de representación diferentes a las descritas en De formas particulares de representación con un esquema comunal y local de representación y De representaciones por consenso normado, 1) y 2) respectivamente, son traídas a colación por Mockus: 3) como ornamento que se produce en una escena y reproduce una escena en la que el actor, orador, y demás, vincula a un otro desde la emoción o el entendimiento a la misma, y 4) como presentificación, en la que aquello que es representado aparece, se hace visible de manera nítida en la escena estableciendo un vínculo entre los asistentes a la escena con el origo y por la experienciación de ese origo común, vínculo constitutivo de comunión entre sí cada vez que se realice la representación.

\section{Diversidad, convergencia y vínculos con la tradición}

Al considerar cada una de las evidencias, ocurriendo en la clase de matemáticas como una puesta en escena de una obra cuyo libreto ha sido configurado de manera cuidadosa y exhaustiva por el profesor para que él mismo y los otros actores deban y puedan usar unos recursos representacionales semióticos específicos, y deban y puedan ejercer e intercambiar sus papeles, incluso el rol de autores. Parece claro que cada una de las representaciones en escena han sido puestas acudiendo al principio de la comprensibilidad, estas deben ser comprensibles y en búsqueda de comprensión de ciertos recursos semióticos. Con cada recurso semiótico empleado en la obra que está emergiendo, y que en tanto totalidad intenta converger hacia un lugar, hacia un cierto significado, parece claro que, en la clase de matemáticas aquí explorada, la representación como ornamento ha tenido ocurrencia.
¿Y el origo, el vínculo con el origo, en qué medida se ha logrado?, ¿qué sucesos pueden atestiguar ocurrencias de la representación como presentificación?, se intentará responder esta pregunta al tiempo de traer a colación algunos hechos que podríamos calificar como pertenecientes al origo de lo tratado.

Primero, según Romero y Bonilla (2008, p. 13) medios y duplos son tratados como nociones comunes en esa primera "axiomatización" euclideana de una forma de matemática presente en el antiguo Egipto:

Un modo egipcio de pensar es sintetizado, sistematizado, en las nociones comunes propuestas por Euclides en sus Elementos. Miremos la quinta y la sexta según Euclides (1991, p. 200):

5. Y las mitades de una misma cosa son iguales entre sí

6. Y los dobles de una misma cosa son iguales entre sí

Como se vio anteriormente, en la actividad para profundizar La tira de papel los estudiantes dieron algunas respuestas a "qué sucedía cuando se hacía un doblez en dicha tira", la siguiente es una de esas respuestas:

Si hago un nuevo doblez, obtendré dos partes iguales, y si hago otro doblez, esta parte se divide en dos y obtendré dos partes iguales.

En ella, un estudiante elucida tanto la relación multiplicativa, por cada nuevo doblez se obtienen dos partes, como la igualdad de las dos partes obtenidas. Aunque los estudiantes no asumen la actitud axiomática manifiesta en el texto euclideano, han entrado en contacto con la verdad de esta afirmación, no siempre presente para los niños ya que ello implica poner en juego la distinción de dos medidas diferentes, como lo atestiguan Romero y Mora (2004)

Segundo, Romero (2003, p. 204) afirma:

(...) Bunt \& otros (1988, pp. 2-3) presentan el hallazgo del arqueólogo Karl Absalon 
en 1937 como un descubrimiento excitante “(...) un hueso de lobo prehistórico de 30000 años de antigüedad, (...) cincuenta y cinco marcas, en grupos de cinco, cortadas en él. Las primeras 25 separadas del resto mediante una doble hendidura (...)" en el que tal vez sea posible "reconocer (...) la idea de correspondencia uno a uno (...) y de una base para un sistema de numeración".

Si estos autores tienen razón, en ese hueso se registró una situación que, vista hoy, es una precursora compleja de la recurrencia en dos sentidos: a) recurrir a añadir uno, "uno más" para conformar una colección b) recurrir a las colecciones así construidas para construir nuevas unidades, "unidades múltiples". Estas colecciones vistas como un uno, sirven de insumo para recurrir al procedimiento que genera el sentido a), constituyéndolas en "uno más", dispuesto para iterar el proceso que genera el sentido b).

El autor subraya sobre la configuración de un sistema, mediante un procedimiento recursivo de unidades de unidades, y que la situación descrita por Bunt y otros, puede ser tomada como una precursora compleja de la recurrencia actual. De esta manera, en las actividades Viaje a Egipto y Granos, el énfasis sobre la toma de conciencia de este tipo de recursión y su relación con las unidades de unidades puede interpretarse como un vínculo con formas arcaicas de hacer y de pensar.

Tercero, Becerra y Romero (2008, p. 6) encuentran en Euclides (1994) series de magnitudes o de números obtenidas de forma que sus elementos consecutivos están en proporción continuada. En tanto sus elementos consecutivos guardan la misma razón, a esta última se le puede caracterizar como una unidad similar descrita en Confrey (1994, pp. 311-312) con respecto a los números enteros como:

(...) en un mundo n-similar, donde la acción sucesora es multiplicar por $\mathrm{n}$, la unidad es $\mathrm{n}$. En la similaridad, $\mathrm{n}$ puede ser vista como la acción multiplicativa invariante entre sucesor y predecesor. [...] llamamos la unidad en el mundo similar una unidad de crecimiento.

Ahora bien, además de la proporción continua$\mathrm{da}$, estas series admiten una forma constructiva por agregación. A partir de un elemento de cada serie, de manera iterativa se genera y agrega el correspondiente gnomon para obtener el siguiente elemento de la serie. De este proceder se obtienen dos ganancias, vínculo de números y magnitudes con formas específicas, y vínculo de la multiplicación con una forma de suma que no conduce a sumandos extensivamente iguales sino a formas recursivamente iguales; una de las definiciones usadas por los griegos, como lo describe Puertas en Euclides (1991, pp. 265-266):

La referencia más antigua al gnomon que conocemos se encuentra en Heródoto (II 109 ) «...los griegos aprendieron de los babilonios el pólos, el gnomon y la división del día en doce partes» (...) más tarde encontramos otra definición en Herón de Alejandría, (...) como cualquier figura que añadida a otra, hace la figura entera semejante a la primera

Al examinar la representación de 243 en base 3 presentada en la figura 8 como evidencia de la presencia de una representación vinculante con tal origo aristotélico. Se analiza esta representación en términos de iteraciones que relacionan gnomones con elementos para generarse de forma recursiva y mutua.

El análisis anterior sirve también para vincular sucesos de clase que permitieron generar la representación analizada, con usos de la unidad similar destacados en Euclides (1994) para la construcción de formas multiplicativas, según Becerra y Romero (2008, pp. 6-7)

Este análisis evidencia la unidad similar como constructora de formas de multiplicación, que permite aumentar la colección sin alterar su estructura multiplicativa, y pone de relieve una conexión entre multiplicación repetida, razones e intervalos de razones iguales y de igual numerosidad. 
Cuarto, Bonilla y Romero (2008, p. 13) muestran usos que Euclides (1991) hace de la mediación y la duplicación en argumentos y operaciones en la geometría euclideana:

(...) bisecar rectas y ángulos para producir perpendiculares, y por lo tanto ángulos rectos; probar relaciones aritméticas entre cada ángulo externo y sus correspondientes ángulos internos y opuestos. Es decir, intervienen en la actividad operativa y en la argumentativa para obtener dos relaciones supremas: la pitagórica y la invarianza de la suma de los ángulos internos de todo triángulo.

Asimismo, se presentan evidencias del uso argumental de distintas unidades similares, desde una de sus representaciones veces $X$, en argumentos generados por los niños, en distintos momentos de la clase de matemáticas mientras matematizaban. Tres estudiantes, respectivamente, argumentan:

5 veces $X 2$ no da igual que 2 veces $X 5$, porque si multiplico 2 X 2 me da 4 y si sigo multiplicando por 2 me da 325 veces X 2, y si multiplico 2 veces X 5 me da 25 y entonces no es igual.

La forma más rápida para escribir las operaciones es 4 veces $X 2$, porque 4 veces $X 2$ lo multiplico y me da el resultado que necesito. Ejemplo 2 X 2 X 2 X $2=16$

5 veces X 2 es igual a $2^{5} \quad 2 \times 2=4 ; 4 \times 2=$ $8 ; 8 \times 2=1616 \times 2=32$.

2 veces X 5 es igual a $5^{2} \quad 5$ X $5=25 ; \quad 25$ y 32 no son iguales porque son diferentes los resultados de 5 veces X 2 y 2 veces X 5 .

Para pasar del 8 al 32 puedo usar la operación $2^{3} \times 2^{2}, 8 \times 4=32$. Del 9 al $729 ; 3^{2} \times 3^{4} 9 \times 81=729$.

Es decir, en el contexto de la clase, los niños llevan a la práctica la constitución de un ideal cartesiano que entronca razonamiento y cálculo para ganar en precisión y eficacia tanto del que razona como de aquellos que siguen los razonamientos.
Se resalta que la diversidad y cantidad de evidencias puestas a lo largo de la sección 3.3.1. atestiguan que la representación ha sido un medio que vinculó la clase de matemáticas con hechos reseñados como pertenecientes al origo. Aunque este origo se concibe aquí no como algo quieto e inmutable sino como un ser multifacético y dinámico en consonancia con maneras de ser, de eso que se trata -relación entre dos mundos multiplicativos- en distintas historias y culturas. Ahora bien, si además se toma lo expuesto en la sección 3.2., es posible tener evidencias de la presencia de cuatro concepciones acerca de representación que habitan en Mockus (1988 pp. 1-148) durante esta matematización.

Si bien es cierto, mediante representaciones los niños expresaron, compartieron e hicieron compatibles puntos de vista -que incluyen valoraciones, divergentes o convergentes con relación a lo que les fue dado o pedido-, en tanto que estos puntos de vista, preñados de origo matemático y probablemente lingüístico, así como de procesos de interacción social, emergieron como símbolos dentro de híbridos de sistemas de representación ricos en posibilidades expresivas relacionales, algorítmicas y argumentales propias de las posibilidades dispuestas en el lenguaje matemático promovido por Descartes y usado hoy desde los cursos iniciales de álgebra escolar en el mundo, se puede afirmar, la configuración de un lenguaje local. Es decir, el papel que en la matematización presentada jugó la representación puede ser situado en términos de la configuración de uno o varios lenguajes locales que cumplen condiciones con respecto a lo matemático, a lo lingüístico y a lo interaccional.

En relación a lo matemático, estar conectado a formas específicas de origo matemático, y a formas y prácticas iniciales del lenguaje matemático algebraico actual. De lo lingüístico, permitir pronunciamientos, es decir enunciaciones. Y en relación a lo interaccional, ampliar el sentido del mundo de vida compartido.

Como en esta matematización, la representación ha refractado, y sin embargo hubo acuerdos con relación a cuestiones problematizadas. 


\section{Respecto al tránsito hacia la definición mockusiana de representación}

Con la manera de hacer el tránsito a su definición de representación, Mockus pretende hacer patente que aquello que debe quedar acogido en ella; primero, no radica tanto en la forma, como en el dispositivo de representación y, segundo, radica en su papel; es decir, privilegia una definición técnico-funcional de la misma. En esta manera, expone concepciones de la representación y las funciones que con relación a estas concepciones le han sido asignadas: permitir llegar a lo que realmente es, de manera inmediata, intuir; permitir vincular de manera inmediata los asistentes con el origo, presentificar; medio para lograr adhesión de un auditorio, ornamentar y evidenciar. Precisamente, Mockus percibe su reconstrucción racional de la representación como medio que permite intuir, presentificar y ornamentar, y evidenciar la bondad de su definición de representación como aquello que posibilita transitar hacia ciertos juegos de lenguaje en los que, en casos límite, llegar a acuerdos puede reducirse a un cálculo.

Para este autor, el papel de la representación en el logro del acuerdo estriba en su poder de elucidar las reglas que configuran cada uno de los distintos juegos de lenguaje, cuya forma óptima es similar a la resultante de la construcción racional elaborada por Whitehead y Russell mostrada aquí en 3.1. La forma óptima de ese juego de lenguaje asegura llegar a acuerdos, entre otras razones porque la elucidación de sus reglas constitutivas lo hace disponible para todo sujeto, y porque el uso de estas reglas hace evaluable lo dicho en este juego de lenguaje como un ejercicio de repaso. Con palabras de Mockus (1988, p. 146):

Las reglas de juegos de lenguaje especializados como el cálculo no discriminan entre sujetos: no prescriben usos distintos para sujetos distintos. Por el contrario, su nitidez, su univocidad y su accesibilidad para todo sujeto permiten instaurar un uso que no lleva la marca de las particularidades sociales o personales de quien juega el juego. Se juega de un modo tal, que cualquier otro conocedor del mismo juego de lenguaje podría jugar exac- tamente (y bajo ciertas restricciones debería) jugar exactamente de la misma manera. Más exactamente, el juego debe ser tal, que cualquiera que vuelva sobre los pasos no pueda -salvo error rectificable de una u otra partemanifestar discrepancia alguna.

En la anterior afirmación Mockus plantea tres condiciones necesarias para llegar a acuerdos. Una va sobre la existencia de un juego de lenguaje cuya forma sea nítida, unívoca y accesible -como el de la construcción racional de Whitehead y Russell-. Las otras dos van sobre los jugadores interlocutores; de manera explícita afirma que estos deben tener conocimiento del mismo, e implícitamente formula que deben compartir la representación -desde la cual elucidan reglas del juego-.

Para Mockus, compartir una representación es, entre otras cosas, compartir un punto de vista y aumentar la probabilidad de llegar a acuerdos razonados. La visualización es una clave del compartir, entendiéndose por visualizar lo comprendido por Mockus (1988, p. 128) "[un...] siempre contribuir a formar una experiencia sensible inmediatamente compartida por los interlocutores efectivos", lo cual implica de los interlocutores reconocer y reproducir lo visualizado. Precisamente, Mockus (1988, p.144) ve en el uso de cierto tipo de representaciones un medio para actuar sobre las reglas constitutivas de ciertos juegos de lenguaje:

El incorporar en un juego de lenguaje el uso de figuras, esquemas, diagramas y signos escritos que se ponen ante la vista (de manera fácilmente reproducible y reconocible), es uno de los medios más eficaces para asegurar un seguimiento ágil de reglas que se apartan de los usos ordinarios.

Pero cabe preguntarse en qué es lo que posibilita de manera fácil la reproducibilidad y el reconocimiento, ¿acaso en las figuras, esquemas y signos escritos mismos?, remitiéndose estrictamente a lo dicho en Mockus (1988, p.144):

Las figuras y los signos permiten, además, que se reconozca prácticamente a "simple vista" la 
conformidad o no con las reglas. Facilitan la formulación de las reglas más en términos de un hacer (que se sedimenta completamente en las huellas visibles y relativamente permanentes que deja) que de un decir o pensar.

Solo el uso de la expresión entrecomillada impide responder afirmativamente a la pregunta arriba propuesta. En otros apartes, dicho impedimento parece atenuarse; por ejemplo, en el prólogo a la definición de representación, afirma Mockus (1988, p. 150):

(...) la representación puede comprenderse como lo que permite el acceso a un juego de lenguaje relativamente rígido, que posibilita la derivación de juicios y decisiones de acción obligadamente reconocidos por cualquiera que juegue correctamente el juego. (...) La representación busca configurar condiciones para que se pueda llegar a decisiones o acuerdos plenamente justificables (es decir tales que su justificación pueda llegar a adelantarse satisfactoriamente dentro del mismo juego, o de otro que lo englobe).

Esta atenuación del impedimento está de acuerdo con la pretensión de identificar la dirección en que se mueve el papel de la representación ligándola a propósitos de los sistemas formales; representar teorías de manera segura mediante el sometimiento de la "interpretación" de objetos y relaciones presentes en la teoría a la conformidad con reglas dadas; cambiar el requerimiento de sentido por el requerimiento de la plena movilidad de la representación. Así, el cálculo, en tanto juego de lenguaje, queda como un caso extremo para el papel de la representación, Mockus (1988, p. 166):

Los sistemas formales muestran cuan lejos puede llegar el cálculo sin recurrir en lo más mínimo a lo "representado". En este límite una representación no representa nada. Es el cascarón plenamente movilizable de un juego de lenguaje.

Volviéndose herramienta para hacer con un grado de eficacia en el logro de fines previa y explí- citamente delimitados. Connatural a la pérdida de interés por el sentido y a la introducción de la consideración de los fines, la importancia de la representación se desplaza desde ser medio de expresión para compartir puntos de vista, evidenciar, vincular, ornamentar entre otros, a ser herramienta para lograr ciertos fines (Mockus 1988). A su vez, aparece un doble criterio para enjuiciar la representación: coherencia interna y funcionalidad con relación a los fines expresados. Diseño, cálculo y representación entroncados para lograr un fin específico y delimitado.

\section{Consideraciones a la definición mockusiana de representación}

Después de explorar de manera sucinta la concepción de representación en Mockus y ante la complejidad que proyecta, procediendo a la manera cartesiana, presentamos una lista de dualidades que pueden caracterizarla como un paso previo para deducir efectos pragmáticos de la representación mockusiana.

\section{Algunas características duales de la representación}

- Dualidad arbitrariedad/obligatoriedad en relación a los modos de su producción -en tanto producción humana deliberada y producción vinculada con la tradición originaria-

- Dualidad en la relación idiosincrásica/cultural que devela según Mockus (1988, p. 168) "[que en] la medida en que la producción de representaciones desborda de lejos el ámbito de la actividad individual y es más bien producción y decantación asegurada por el género humano, las dos caras de la representación terminen siendo una sola."

- Dualidad mediador/constitutivo de juegos de lenguaje. Mediador en tanto recurso deliberadamente construido, "el uso de figuras, esquemas, diagramas y signos escritos que se ponen ante la vista (de manera fácilmente reproducible y reconocible) [que por su misma 
eficacia] para asegurar un seguimiento ágil de reglas que se apartan de los usos ordinarios para facilitar cierto juego no es algo accesorio. Hay un momento en que se vuelve condición de posibilidad" (Mockus 1988, p. 144) tornándose constitutiva del juego que, una vez instaurado, a fuerza de costumbre, las presenta como dadas con plena autarquía. ${ }^{4}$

- Dualidad mediador/constitutivo de la plena disponibilidad a la discusión racional de lo representado. Mediador en tanto dispositivo que hace visible ciertas características, y constitutivo de intuibilidad espacial -en tanto figura- o temporal -en tanto ejemplo, símbolo, construcción o esquema- (Mockus 1988, pp. 182-183).

- Dualidad proceso/producto. Según Mockus (1988, p. 153) "La representación [...] es en general una drástica reestructuración" de lo representado, que es perfectible en el sentido lakatosiano "[...] en el que "la "representación" surge, o por lo menos se afina, en el proceso de discusión racional" (Mockus 1988, p. 161).

- Dualidad proceso/producto. Representación como proceso de representar vs. representación como dispositivo de representación (Mockus 1988, p. 155).

- Dualidad representación/presentificación, en la medida en que lo actuado sobre la representación guía la actuación sobre lo representado.

- Dualidad inmediatez/preparación en la posibilidad de captación e intuibilidad.

4. Este efecto sucedió en la representación de la música: cuando un buen violinista utiliza su gama al emitir dos notas sucesivas, la segunda ha sido entendida en los armónicos de la primera. Este no es el caso de la gama templada, esta es falsa del punto de vista musical, y fue considerada como una monstruosidad en el siglo XVIII pero es la única utilizable en instrumentos a sonidos fijos, si no tocaría multiplicar las teclas de un piano situadas en la octava, o las claves de los instrumentos de viento volviéndolos intocables.

\section{Algunos efectos pragmáticos de la representación}

Dado que cada dualidad está remitida a cierto propósito, es una mediación que requiere y permite interpretación en contextos existentes y posibles de experiencia humana. Recorriendo de arriba hacia abajo y de abajo hacia arriba la presentación de las dualidades en tanto mediaciones, se recupera de manera sintética, como "intuición intelectual cartesiana”, el carácter pragmático de la representación. Sintaxis, semántica y pragmática se hacen presentes en ella. Así entonces, permiten:

a) Coordinar series de acciones organizando la acción.

b) Transformar las interpretaciones de la organización de la acción reorganizando la acción (Mockus 1988, p.152).

c) Juegos de lenguaje orientados al diseño cuyo sentido puede estar dado, más que en términos de referencia o mera sintaxis intralingüística, en términos de consecuencias para la acción que, a partir de un mínimo de supuestos expresados con máxima precisión, apuntan a regular de manera explícita:

- Significado.

- Argumentación.

- Derivación del máximo de conexiones necesarias (Mockus 1988, pp. 151-155).

d) Pasar desde juegos de lenguaje a otros orientados a la comprensión e intuibilidad de lo arcaico y lo proteico (Gadamer 1977/2003).

- Transformando sentidos previos e instaurando nuevos sentidos

- Posibilitando comprensión del camino de transformación y de instauración

- Permitiendo formas de reflexión respecto de los sentidos de estas transformaciones e instauraciones en dirección a sentidos originarios. 


\section{Objeción a la representación mockusiana}

Según lo dicho en las consideraciones a la representación mockusiana, en las dualidades que la caracterizan, así como en sus efectos pragmáticos, se advierte, tal como lo afirma Mockus (1988, p. 168), una tensión entre "el reconocimiento de la representación como obra humana fundada en el sujeto" y la "otredad vinculante de la representación".

En la trama de su reconstrucción racional acerca de la representación, dicha tensión se inclina a veces hacia un polo y a veces hacia el otro. Así, cuando en aras de sostener límites al papel que le adjudica a la representación para el logro de acuerdos compartidos Mockus (1988, p. 157) pregunta: “qué pasa cuando no se dispone de representaciones aceptables para todos los interlocutores involucrados?", su respuesta tiende a desaparecer de la representación el polo de la otredad vinculante; ${ }^{5}$ cuando muestra el papel de la representación en el cálculo, en tanto juego de lenguaje, su enfoque tiende a desaparecer el polo subjetivo. Mockus (1988, p.147):

No se trata de un uso impersonal del lenguaje donde se borra toda especificidad de los interlocutores. El otro pierde su otredad y deviene un "uno", un yo descentrado y generalizado. Tal vez una huella gramatical de este giro es la exclusión del "yo" y el "tú", o su marginación a un papel muy auxiliar. La posibilidad de "ponerse en el lugar de otro" se radicaliza y ese movimiento se convierte en inmediato.

Cierto es, como antes se ha dicho, que Mockus (1988, p. 168) afirma la posibilidad de que "las dos caras de la representación terminen siendo una

5. (Mockus 1988, p. 157) presenta dos alternativas: la probable derivación hacia la percepción de un fracaso de la opción de llegar a acuerdos provocado conscientemente, o "terminar promoviendo [...] una adopción acrítica de representaciones" matizadas con la presencia de dos proyectos relativamente contradictorios; del proyecto habermasiano de la constitución de la esfera pública cuya existencia supone la vindicación de las pretensiones de validez apoyada en el uso de discursos sistemáticos y de proyecto marcusiano centrado en el papel subversivo de formas de arte que yendo contra la unidimensionalidad del hombre actual se dirija hacia el encuentro estético del ser humano y hagan la verdad artística otra vez comunicable. sola”. Hasta donde se logra entender, no desarrolla esta opción, aunque parece basarla en reconocer al sujeto como fundamento de la representación, y a la permanencia de la otredad vinculante de la representación en tanto que la relación del individuo con la representación se da en el ámbito de la relación del individuo con lo social. En palabras de Mockus (1988, p. 168):

(...) la relación del individuo con la representación (tomada incluso en el sentido más específico que hemos intentado atribuirle) se inscribe en la relación del individuo con lo social -y con lo sagrado si se entiende éste como lo entendió Durkheim-.

Con todo, es el papel de la representación con relación a la regla elucidada y a su elucidación lo que parece gobernar la posibilidad de llegar a acuerdos. Es decir, Mockus parece centrar la posibilidad de lograr acuerdo en la capacidad que porta la representación para generar juegos de lenguaje explícitamente regulados, de tal manera que en la mera disposición de un asunto problematizado en ese lenguaje, aparezca ya una solución que será aceptada por todos debido a que a ella llegará cualquiera que sepa seguir las reglas que lo constituyen. Así, la representación puede ser pensada como aquello que conduce a los partícipes a someter su actuar a conformidad con reglas.

Por una parte, sin duda, una vez se conocen un juego de lenguaje tal y las representaciones que a este conducen o lo constituyen, y se acepta por los participantes que lo problematizado sea dispuesto en ese juego de lenguaje o en otro que lo englobe, la solución a la que se llegue está en conexión con el planteamiento del problema y aumenta la probabilidad de que ella sea ratificada. Así pues, una representación posibilita llegar a acuerdos acerca de una cuestión problematizada cuando los participantes ya comparten, en términos de aceptación, recursos previos que permiten configurar o comprender dicha representación.

Por otra parte, con respecto a la comprensión de la representación como aquello que permite el proceso paulatino de desambigüedad de significado, 
hasta, en casos extremos pero deseables, lograr el desplazamiento del requerimiento de sentido así como la instauración de procedimientos algorítmicos para la toma de decisiones y argumentaciones ratificables. Entonces, el uso de representaciones para objetivar aquello sobre lo que los interlocutores están poniéndose o deben ponerse de acuerdo para actuar, dan inicio a un proceso de representación que conduce a un cierto juego de lenguaje, un lenguaje local. Esto no conlleva la pérdida de sentido de la representación, solo que en el proceso asume el sentido que expresa la tensión de la relación entre el lenguaje local y los lenguajes más generales con los que este se conecta.

Al poner las dos partes juntas se ve que la representación es aquello que permite a los interlocutores disponer un acuerdo previo e ir configurando un proceso de elaboración comprensión y valoración de una problemática específica y de su solución mediado por representaciones. Los interlocutores, en dicho proceso, solo pueden recurrir a generar, dilucidar y relacionar representaciones mediante el uso de instrumentos conectándose por ello a procesos y significaciones culturales. Es decir, los interlocutores entran en procesos de generación de sentido tensionados por significaciones culturales que, por estar mediados por las comprensiones y valoraciones de los interlocutores, deben tener, además, un carácter local, aunque después puedan ser públicamente tematizados como parte de la experiencia humana y se le pueda intentar extender y generalizar.

Puesto así, para los interlocutores, la representación de partida es un emergente que involucra algunos de sus puntos de vista con respecto de la cuestión problematizada. Estos puntos de vista no necesariamente son compartidos.

El carácter local del proceso es obligado, en la medida en que en la representación habitan las interpretaciones de los interlocutores mediadas por su capacidad y posibilidad de uso de los instrumentos para incorporar en la representación emergente sus puntos de vista en relación a la cuestión problematizada.
El carácter cultural del proceso es obligado, en la medida en que los instrumentos de representación, así como el uso de los mismos, están culturalmente dispuestos y significados.

Por lo tanto, la representación es aquello que los interlocutores configuran usando recursos previos compartidos desatando un proceso de representación que genera un contexto, en el sentido bajtiniano, de refinamiento de lenguajes locales que permiten disponer y transformar la problemática según el sentido previsto en el lenguaje local, aunque tensionado por los sentidos promovidos por los lenguajes más generales con los que dichos lenguajes locales se conectan, así como con los instrumentos empleados para representar. Si la tesis durkheimiana se sostiene, las representaciones de los grupos humanos con raíces sociales arcaicas comunes son encarnaciones religiosas cuyo prototipo es el totemismo. Durkheim (1982, pp.177-178):

(...) el totemismo es la religión, no de determinados animales $\mathrm{u}$ hombres, o imágenes, sino de una especie de fuerza anónima e impersonal, que se encuentra en cada uno de estos seres, sin que sin embargo se confunda con ninguno de ellos. Ninguno la posee por entero y todos participan de ella. Ella es totalmente independiente de los seres en los que se encarna, que los precede y los sobrevive. Pero esta fuerza permanece actual, viva e idéntica a sí misma. Es la que anima a las generaciones de hoy en día, de igual manera que animaba a las de ayer y animará a las de mañana.

Esta idea durkheimiana de religión asegura que el colectivo vuelve sagrado al poder omnipresente de la tribu, que rebasa las posibilidades de todo individuo, pero que también lo resguarda y le confiere identidad. El vínculo con el origo que la representación logra sería una manifestación de ese sentido sacro originario.

En 3.2. cuando se muestra que no es plausible pensar la representación cartesiana como un asunto de reflejo, además de presentar la advertencia que Mockus realiza, se introdujo en 3.2.1. una suerte de análisis de la representación en un proceso de 
matematización en un aula. Se identificó que los niños configuraron sistemas de representación, expusieron diversidad de representaciones frente a los mismos asuntos tematizados haciendo patente sus diversos puntos de vista. Se encontró también que hubo formas específicas de convergencia desde la diversidad representacional existente auspiciada por el diseño de la clase previsto por el profesor, logrando llegar a un acuerdo negociado de una simbolización aritmética cuya referencia involucra buena cantidad de la vida escolar, donde emergieron soluciones a las distintas tareas propuestas.

El proceso de negociación muestra argumentaciones realizadas por los niños que ponen claridad sobre el hecho que, para ellos, la simbolización aritmética minimal, aunque sometida a sintaxis, y por lo mismo enraizada en la forma, al capturar gran parte de la actividad (su actividad) puesta en marcha y configurada a lo largo del hacer escolar propuesto, también está enraizada en la semántica. Dicha representación aritmética puede ser vista como una forma producto de condensación de la vida escolar de la que fue emergiendo. También arroja luz sobre la existencia de hechos de presentificación, y además, sobre una manera de llegar a acuerdos que no supone pérdida ni desplazamiento de los sentidos previos dados a una representación, pero sí su permanencia y ampliación según el lenguaje local, también emergente, que la transforma o acoge.

Así, con relación a la definición mockusiana de la representación y su papel en la construcción de acuerdos razonados, lo aquí presentado abre interrogantes acerca del progresivo desplazamiento del requerimiento de sentido de la representación en aras de la movilidad de la representación dentro del juego de lenguaje, como sucedería con los sistemas formales y dentro del cálculo. Sin embargo, para una discusión parece pertinente profundizar en dos concepciones de la representación, incluso anunciadas por Mockus, ligadas a la sacralidad -siguiendo a Durkheim- y la comprensibilidad -siguiendo a Gadamer-.

Esta discusión, desde otro punto de vista, puede abordarse desde la problemática de la construcción y transformación de los algoritmos y de los usos para ellos pensados. Dicha construcción correspondería a una matematización cuyo carácter debe conectarse, aunque también diferir, con la aquí mostrada.

\section{Acerca de lo que fue matematizado}

La actividad representacional documentada ocurrió en un curso de matemáticas que matematizaba. Se matematizó una relación, una cuestión que, según Mockus (1988), para Leibniz es una clase de extensionalización. Una relación entre dos tipos de mundos generados, uno por iteración de unidades aditivas y el otro por iteración de unidades multiplicativas.

Las sesiones de clase conformaron una secuencia unitaria; la actividad en ella desarrollada justamente fue una actividad de matematización. Así que, la matematización incorporó componentes rituales -secuencias de acciones siempre presentes y estereotipadas, por lo tanto normadas, con intención de convocar a la comunidad a establecer vínculos con ciertos orígenes, verdaderos acervos culturales, o historias de aquello que se matematiza- y cúmulos de:

1. Acciones (doblar papel, contar dobleces, escribir datos, llenar tablas, representar, entre otros).

2. Puntos de vista expresados en las representaciones (acerca de objetos: escuela, guardería, acerca de relaciones: entre cantidades, entre distintos tipos de unidades).

3. Vínculos entre las acciones y las representaciones (acciones físicas realizadas y representadas sobre papel, acciones físicas no realizadas representadas con signos, acción de representar y las acciones representadas).

4. Vínculos entre las representaciones (entre íconos, índices y símbolos configurando signos; entre signos, y otros).

5. Vínculos entre enunciados, enunciaciones, diálogos (los enunciados de cada actividad, los 


\section{Revista Científica No. 11 Contenido}

EDITORIAL

Dra. Patricia Gallego Torres

ENSEÑANZA DE LAS CIENCIAS

Una educación estadística: para una sociedad que tolere la incertidumbre

A statistical education: for a society that tolerated uncertainty PEDRO ROCHA SALAMANCA

Pautas de validez de los contenidos en las clases de ciencias: una aproximación al problema de los criterios de validez del conocimiento escolar

Guidelines of validity of the contents in the classes of sciences: an approach to the problem of the criteria of validity of the scholastic knowledge

CARMEN ALICIA MARTÍNEZ RIVERA - ANA RIVERO GARCíA

Tras las huellas de la investigación en educación de la física desde los proyectos del IDEP, el CIUP y la Universidad Distrital Francisco José de Caldas en la década 1995-2005

Following tracks of the investigation in physical science education from the researches projects of IDEP, CIUP and Universidad Distrital Francisco José de Caldas during 1995-2005 decade. JAIME D. REYES R

Una aproximación a un estado del arte de la educación energética An approach to a state of the art of education energetic JOHN E. CASTRO M.

Una alfabetización científica tecnológica y cultural

A technological and cultural scientific alphabetization ADRIANA PATRICIA GALLEGO TORRES - JAIR ZAPATA P - MONICA RUEDA PINTO

El conocimiento profesional de los (as) profesores (as) de ciencias: algunos aspectos centrales en el desarrollo

de la línea de investigación

The professional knowledge of (as) the professors (as) of sciences:

some central aspects in the development of the line of investigation CARMEN ALICIA MARTÍNEZ RIVERA

Propuesta didáctica para el aprovechamiento educativo de

la visita a un parque temático y generar actitudes positivas hacia el aprendizaje de las ciencias GERMÁN LONDOÑO V.- JORDI SOLBES M. - ANA PATRICIA LEÓN U.

Reflexión acerca de la formación de ingenieros y la educación energética Reflection about the formation of engineers and education energetica JAIR ZAPATA PEÑA - JHONN E. CASTRO M - ALEXANDER AGUDELO

Estructura de las prácticas docentes en probabilidad y estadística en las facultades de ingeniería en Bogotá, Colombia Structure of the educational practices in probability and statistics in the powers of engineering in Bogota, Colombia PEDRO ROCHA SALAMANCA
Los textos de los articulos de esta publicación pueden ser reproducidos citando la fuente. Los juicios emitidos por los autores son de su responsabilidad, por lo tanto no comprometen a la Universidad Distrital Francisco José de Caldas, al Centro de Investigaciones y Desarrollo Científico ni al Comité Editorial. 
pronunciamientos de los diversos estudiantes a cada actividad).

6. Relaciones complejas entre los objetos matemáticos en emergencia y los instrumentos de matematización (para el caso, exige amalgamiento entre distintos tipos de relación entre suma y multiplicación reiterada; algunos símbolos que posibilitan la matematización inicialmente son ajenos a los estudiantes que matematizan; la relación a matematizar inicialmente es ajena a los estudiantes que la matematizan).

7. Juegos de lenguaje, relacionados con lenguajes locales tensionados por las historias de los constructos matemáticos emergentes (veces $x$, a cada uno le corresponden tantos; a la parte anterior la multiplicamos por y resulta...; para pasar de ... a .... podemos multiplicar por ...; "5 veces X 2 es igual a $\left.2^{5} ; \ldots\right)$.

Por una parte, las valoraciones acerca de lo correcto, lo conveniente, lo eficaz, lo estético, y otros, integraron la configuración de estos puntos de vista $y$, por lo tanto, las representaciones realizadas expresan vínculos con el mundo de vida de sus autores; también, los formatos de las representaciones fttabulares, diagramáticos (árbol, combinatorios), gnomónicos, recursivos; verbales, numéricos, y otrosft en tanto modos de expresión, permiten develar la existencia de vínculos con distintas formas originales, origos, acervos culturales, del objeto matemático cuya emergencia ha sido propuesta y estimulada. Por otra parte, en tanto se puede afirmar, con plausibilidad, es decir, con certeza, que durante la clase de matemáticas la actividad representacional condujo a la configuración de los cúmulos de los vínculos arriba mencionados y descritos, esta, la clase de matemáticas, obedece a nuestra interpretación de contexto bajtiniano, en este documento página 1 :

(...) entonces, podemos visualizarlo como una figura emergente, tridimensional y recursiva de relaciones pragmáticas y semióticas compartidas cuando dos hablantes, al compartir situaciones específicas, comparten sus horizontes espaciales, sus comprensiones y conocimientos, así como sus valoraciones, ya que, al hacerlo, deben recurrir a las relaciones pragmáticas y semióticas previamente compartidas con y por otros hablantes, actualizándolas en un espacio-tiempo específico.

Así, la matematización lograda -vista como proceso/producto emergente- es emergente de un emergente: la clase de matemáticas como contexto bajtiniano. Este contexto es, a la vez, tanto producto del azar como de la planificación detallada. De forma más precisa, es producto del diseño de un profesor que favorece y prevé como importantes, definitivas, dimensiones propias de la actividad representacional (D’Amore y Santi, 2010; Font, Godino y D'Amore, 2010) como parte de las relaciones pragmáticas y semióticas.

\section{Bibliografía}

Becerra, M. y Romero, J. (2008). Unidad similar en la construcción de la multiplicación: Una mirada a los elementos. En García, G. (comp). Memorias IX Encuentro colombiano de matemática educativa. Valledupar: Asocolme.

Bajtín, M. (1982). Estética de la creación verbal. (Bubnova, T., trad.) México: Siglo XXI.

Bajtín, M. (1986). Problemas literarios y estéticos. (Caballero, A., trad.) La Habana: Arte y Literatura.

Benveniste, E. (1966). Problèmes de lingüistique générale. Paris: Gallimard. V1.

Bonilla, M. y Romero, J. (2008). Pensamiento multiplicativo y álgebra escolar. Algunas relaciones. En Memorias XXIII Coloquio distrital de estadística y matemáticas. Bogotá: Universidad Pedagógica Nacional.

Bunt, L.; Jones, P. \& Bedient, J. (1988). The historical roots of elementary mathematics. New York: Dover. (2 Edición).

Cárdenas, A. (2009a). Notas sobre Bajtín. Notas de clase Seminario Lenguaje, formación y sujeto. 
(Agosto-Diciembre de 2009). Universidad Pedagógica Nacional. Bogotá: material inédito.

Cárdenas, A. (2009b). El lenguaje y la literatura en Bajtín. Notas de clase Seminario Lenguaje, formación y sujeto. (Agosto-Diciembre de 2009). Universidad Pedagógica Nacional. Bogotá: material inédito.

Cobb, P.; Confrey, J.; Disessa, A.; Lehrer, R. \& Schauble, L. (2003). Design experiments in education research. Education Researcher. 32 (1): 9-13.

Confrey, J. (1994). Splitting, Similarity, and Rate of Change: A New Approach to Multiplication and Exponential Functions. En Harel \& Confrey (Eds.) The development of multiplicative reasoning in the learning of mathematics. New York: State University of N.Y.

D' amore, B. \& Santi, G. (in press). Objectification and Semiotic Function.

Durkheim, E. (1912/1982). Las formas elementales de la vida religiosa: el sistema totémico en Australia. Madrid: Akal.

Euclides (1991). Elementos. Libros I-IV (PUERTAS, M., Trad.). Madrid: Gredos.

Euclides (1994). Elementos. Libros V-IX (PUERTAS, M., Trad.). Madrid: Gredos.

Font, V.; Godino, J. \& D' amore, B. (in press). Representations in mathematics education. An onto-semiotic approach. En: Jornal Internacional de Estudos em Educação Matemática.

Gadamer, H. (1977/2003). Verdad y método: fundamentos de una hermenéutica filosófica (Aparicio, A. y Serrano, R. trads.). Salamanca: Sígueme.

Habermas, J. (1987). Teoría de la acción comunicativa. Racionalidad de la acción y racionalidad social. Vol. 1. Madrid: Taurus Humanidades.

Mockus, A. (1988). Representar y disponer. Bogotá: Universidad Nacional de Colombia.

Narváez, D., Urrutia, E. y Romero, J. (2005). Símbolos en la construcción de esquemas splitting. En García, G. (comp). Memorias VII Encuentro colombiano de matemática educativa. Tunja: Asocolme.

Romero, J. (2003). La ricursione come modellatrice di situacioni. En: Convegno nazionali Incontri con la matematica, Bologna: Atti del XVII Convengo nazionali Incontri con la matematica.

Romero, J. y Mora, O. (2004). Sobre la normalización de la escritura de las fracciones. En: Revista Científica (6): 274-301.

Whitehead, A.y Russell, B. (1910, 1912, 1913/1962). Principia Mathematica, 3 vols, Cambridge: Cambridge University Press. Standford Encyclopedia of philosophy. Disponible en: http://plato.stanford.edu/entries/principiamathematica/\#COPM 